(2) Open Access Full Text Article

LETTER

\title{
Potential therapeutic hazards due to drug-drug interaction between topically and systemically coadministered medications
}

This article was published in the following Dove Press journal:

Therapeutics and Clinical Risk Management

29 July 2013

Number of times this article has been viewed

\author{
Mei-Juan Lan' \\ Quan Zhou ${ }^{2}$ \\ 'Division of Nursing, ${ }^{2}$ Department \\ of Pharmacy, the Second Affiliated \\ Hospital, School of Medicine, Zhejiang \\ University, Hangzhou, Zhejiang \\ Province, People's Republic of China
}

\section{Dear editor}

We read with great interest the study by Peniston et $\mathrm{al}^{1}$ who performed a randomized controlled trial to examine the frequency and type of adverse events (AEs) in patients with osteoarthritis who received concurrent therapy of topical diclofenac sodium $1 \%$ gel (DSG), and drugs known to have potential drug-drug interactions (DDIs) with diclofenac; and concluded that such co-medication had little impact on the frequency of AEs in this population.

The results of this study ${ }^{1}$ provide very useful information for clinical practice, ie, DSG may be a safe alternative to oral diclofenac when a pain reliever needs to be co-medicated with CYP2C9 substrates like warfarin antidiabetic sulfonylurea derivatives. DDIs between topically and systemically coadministered medications are easily neglected by clinicians, which brings about potential risk of patient safety. Peniston et $\mathrm{al}^{1}$ answered a scientific question in clinical therapeutics. We completely appreciate their rigorous study and original spirit of exploration. We would like to discuss and share our perspectives in the following paragraphs.

The Joint Commission International (JCI) accreditation standard has strict requirements for rational drug use. Appropriateness review of real or potential DDIs among all current medications is a mandatory task for auditing pharmacists. ${ }^{2}$ Peniston et al's study further prompted us to better understand JCI requirements. We performed a PubMed search covering the period from 1988 to 21 June 2013, using the search terms "topical" and "drug interaction" and additional filters (species: humans; languages: English). Nine hundred and twenty-eight articles were detected. Inclusion criteria included studies or case reports describing DDIs between topically and systemically coadministered medications even if results of some clinical trials show no clinical significance. Fifteen articles were finally included under this search strategy. The full text of each article was critically reviewed, and data interpretation was performed. Table 1 lists the literature describing DDIs between topically and systemically coadministered medications, except Peniston et al's study.

For each DDI, the object drug is defined as the medication whose pharmacokinetics and/or pharmacodynamics may be modified by the drug interaction process. The precipitant drug is defined as the medication responsible for affecting the pharmacologic action or the pharmacokinetic properties of the object drug. ${ }^{16}$ Our literature review showed an interesting fact that topically administered medications could play a role of object drug in addition to a role of precipitant. 


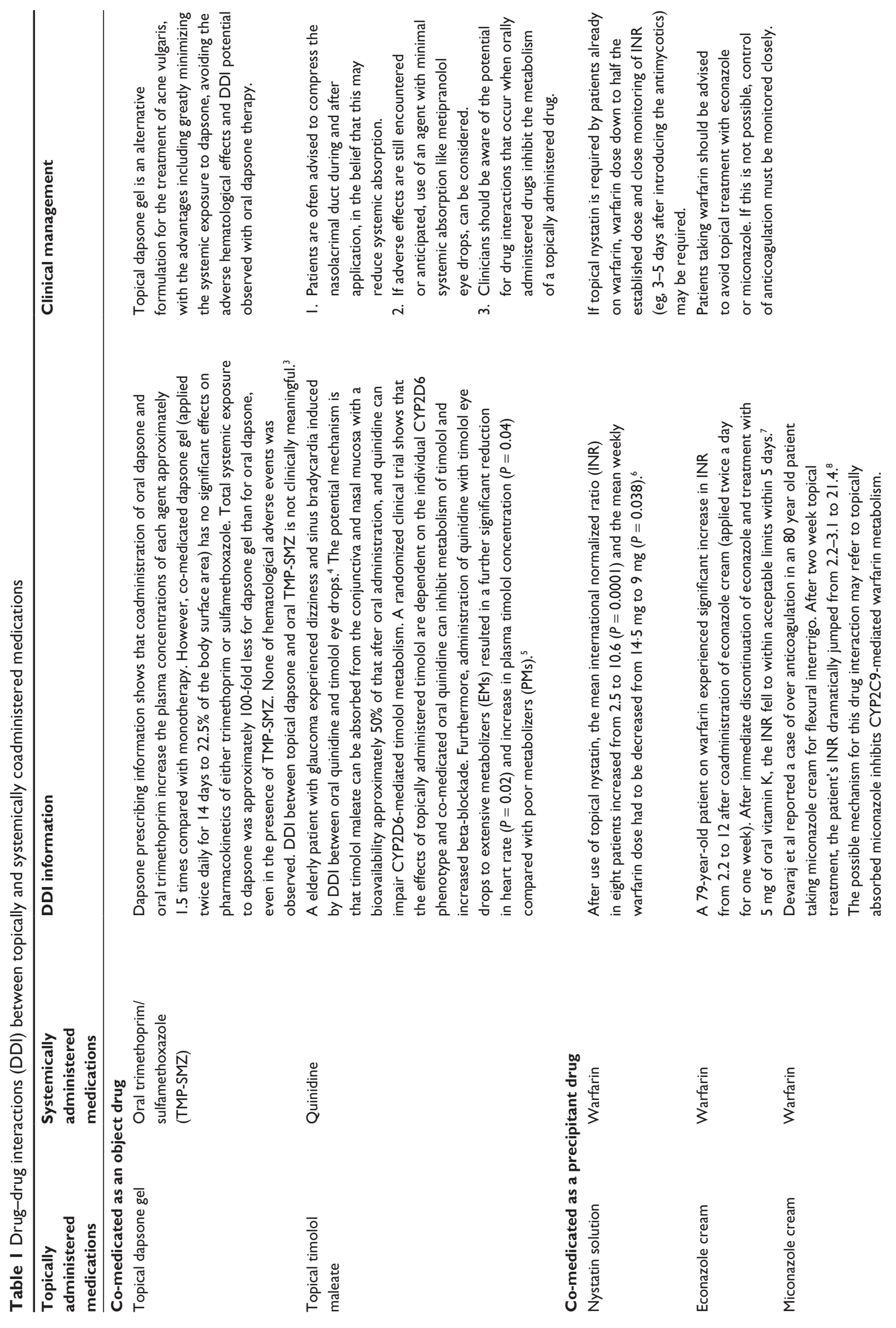




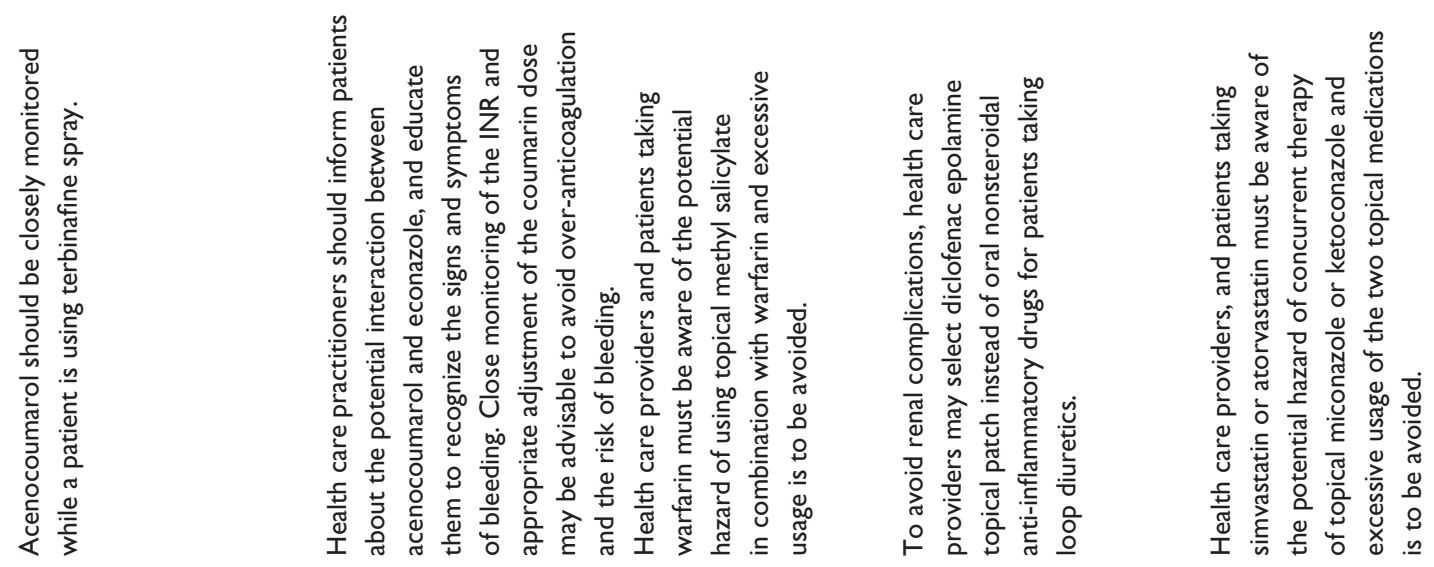

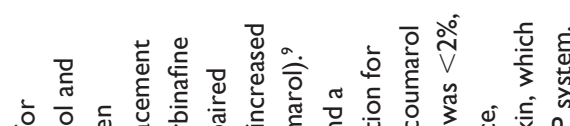

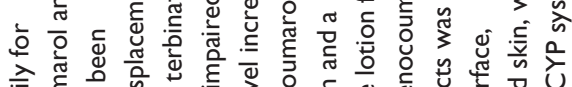

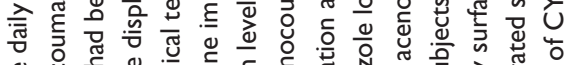
品

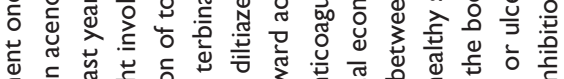

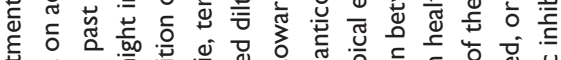

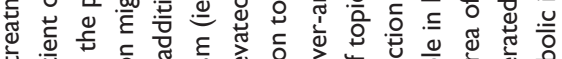

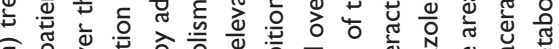

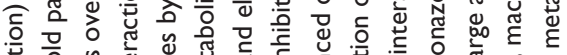

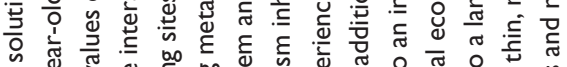

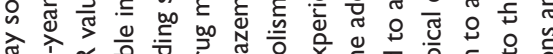

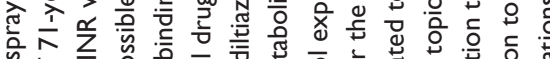
○ั

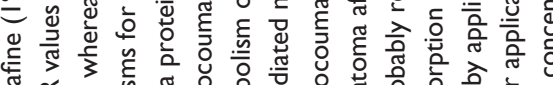

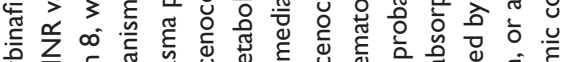

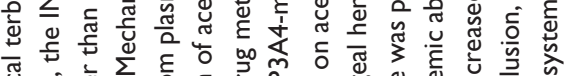

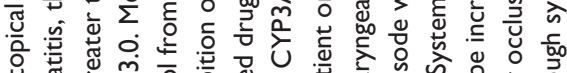

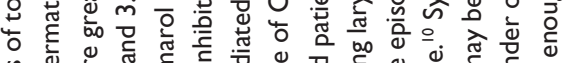

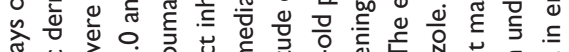

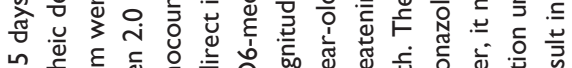

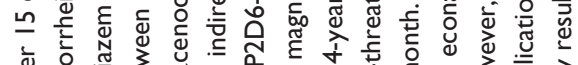

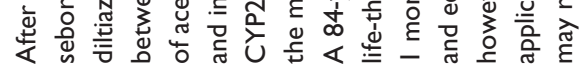
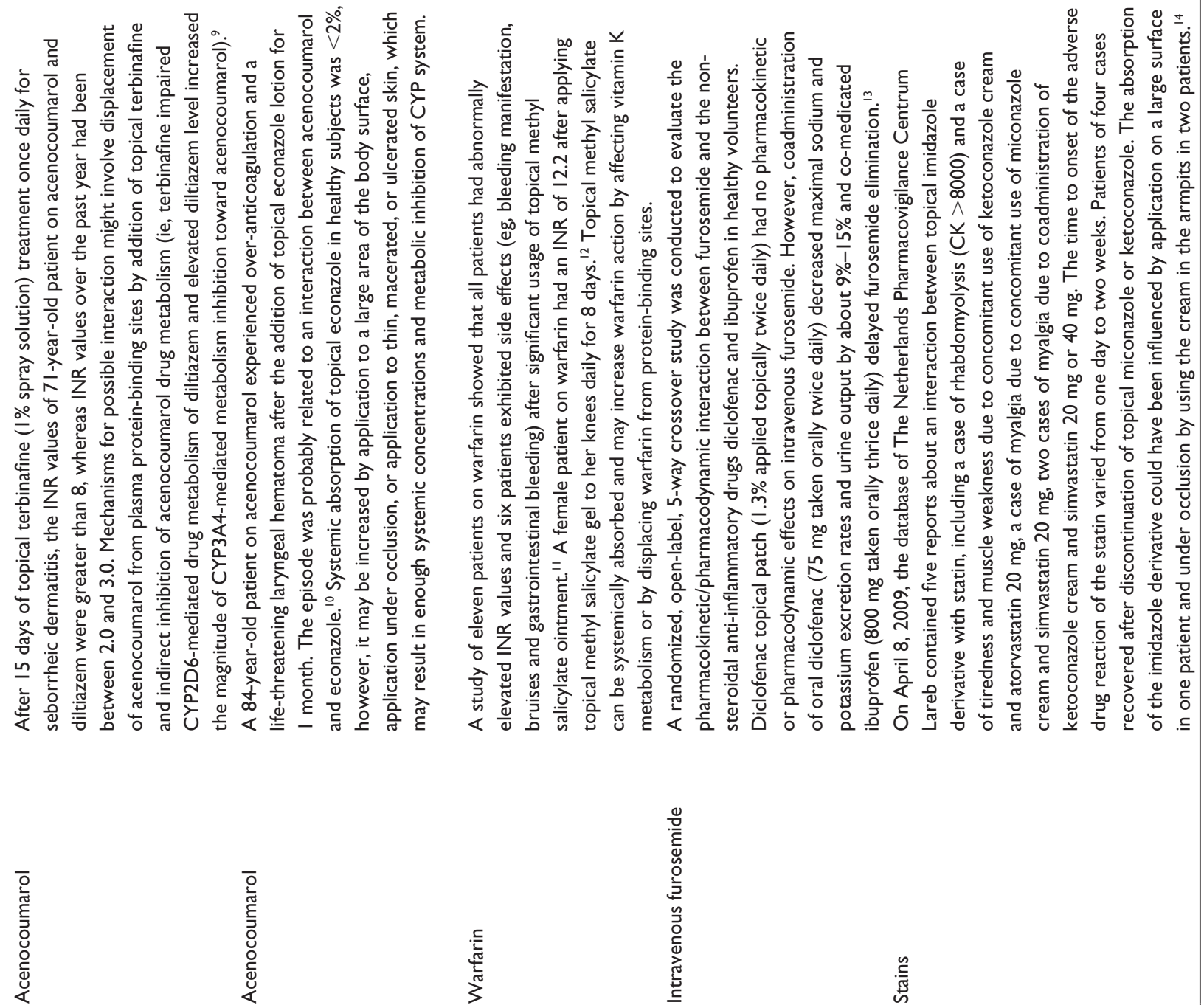

$\stackrel{n}{\stackrel{5}{\sharp}}$
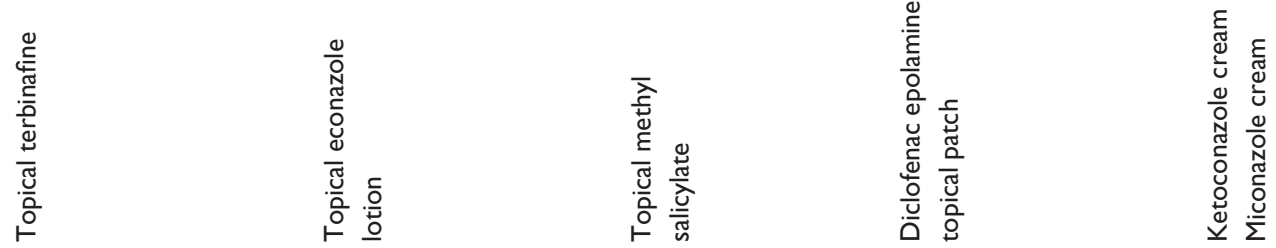
Some factors may influence the likelihood of DDI between topically and systemically administered medications and they are as follows: (1) percentage of body surface area to which the topical formulation is applied; (2) age of the patient - the very old and very young are more likely to exhibit DDI; (3) genetic factors may affect the magnitude of DDI (eg, DDI between timolol eye drops and oral quinidine is dependent on CYP2D6 phenotype; poor metabolizers have a higher risk for DDIs with a low systemic concentration of a topical imidazole derivative than extensive metabolizers do); ${ }^{5,17}$ (4) method of application-medications applied under occlusion are more likely to cause DDI; (5) condition of the stratum corneum-topical formulations applied to mucous membranes, genital skin, or thin, macerated, or ulcerated skin are more susceptible to be systemically absorbed; and (6) other concomitantly used medications are also involved in the DDI mechanism, eg, topical terbinafine (precipitant drug) impaired CYP2D6-mediated drug metabolism of diltiazem and elevated diltiazem level increased the magnitude of CYP3A4-mediated metabolism inhibition toward acenocoumarol (object drug). ${ }^{9}$

Methods used for judging whether there are DDIs between topically and systemically administered medications are as follows: (1) pharmacokinetic interaction study; (2) randomized controlled clinical trials focusing on overall tolerability of topical formulation with concomitant use of systemically administered medication; and (3) case analysis by using the Horn Drug Interaction Probability Scale or Naranjo scale..$^{9,10,18}$

In conclusion, Peniston et al's ${ }^{1}$ study brought an interesting and important topic to clinicians and patients who should be careful of potential therapeutic hazards due to DDIs between topically and systemically coadministered medications.

\section{Acknowledgment}

This work was supported by Zhejiang Provincial Bureau of Health (No 2012KYA090), and Zhejiang Provincial Bureau of Traditional Chinese Medicine (No 2011ZB075).

\section{Disclosure}

The authors report no conflicts of interest in this work.

\section{References}

1. Peniston JH, Gold MS, Wieman MS, Alwine LK. Tolerability of diclofenac sodium $1 \%$ gel with concomitant medications known to interact with diclofenac. Ther Clin Risk Manag. 2013;9:153-159.

2. Joint Commission International. JCI accreditation standards for hospitals [webpage on the Internet]. Oak Brook, IL: Joint Commission International; 2010. Available from: http://www.jointcommissioninternational.org/common/pdfs/jcia/IAS400_Standards_Lists_Only.pdf. Accessed March 20, 2013. 
3. Thiboutot DM, Willmer J, Sharata H, Halder R, Garrett S. Pharmacokinetics of dapsone gel, $5 \%$ for the treatment of acne vulgaris. Clin Pharmacokinet. 2007;46:697-712.

4. Higginbotham EJ. Topical beta-adrenergic antagonists and quinidine. A risky interaction. Arch Ophthalmol. 1996;114:745-746.

5. Edeki TI, He H, Wood AJ. Pharmacogenetic explanation for excessive beta-blockade following timolol eye drops. Potential for oral-ophthalmic drug interaction. JAMA. 1995;274:1611-1613.

6. Kovac M, Mitic G, Kovac Z. Miconazole and nystatin used as topical antifungal drugs interact equally strongly with warfarin. J Clin Pharm Ther. 2012;37:45-48.

7. Lang PG Jr, LeClercq AH. Increase in anticoagulant effect of warfarin in a patient using econazole cream. J Am Acad Dermatol. 2006;55: S117-S119.

8. Devaraj A, O’Beirne JP, Veasey R, Dunk AA. Interaction between warfarin and topical miconazole cream. BMJ. 2002;325:77.

9. Morales-Molina JA, Arrebola MA, Robles PA, Mangana JC. Possible interaction between topical terbinafine and acenocoumarol. Ann Pharmacother. 2009;43:1911-1912.

10. Wey PF, Petitjeans F, Lions C, Ould-Ahmed M, Escarment J. Laryngeal dyspnea in relation to an interaction between acenocoumarol and topical econazole lotion. Am J Geriatr Pharmacother. 2008;6:173-177.

11. Joss JD, LeBlond RF. Potentiation of warfarin anticoagulation associated with topical methyl salicylate. Ann Pharmacother. 2000;34:729-733.
12. Yip AS, Chow WH, Tai YT, Cheung KL. Adverse effect of topical methylsalicylate ointment on warfarin anticoagulation: an unrecognized potential hazard. Postgrad Med J. 1990;66:367-369.

13. Paterson CA, Jacobs D, Rasmussen S, Youngberg SP, McGuinness N. Randomized, open-label, 5-way crossover study to evaluate the pharmacokinetic/pharmacodynamic interaction between furosemide and the non-steroidal anti-inflammatory drugs diclofenac and ibuprofen in healthy volunteers. Int J Clin Pharmacol Ther. 2011;49:477-490.

14. Topical imidazole derivatives and drug interactions. Available from: http://www.lareb.nl/larebcorporatewebsite/media/publicaties/ kwb_2009_3_imida.pdf. Accessed April 8, 2009.

15. Renoult E, Hubert J, Trechot P, Hestin D, Kessler M, L'Hermite J. Effect of topical rifamycin SV treatment on cyclosporin A blood levels in a renal transplant recipient. Eur J Clin Pharmacol. 1991;40(4): 433-434.

16. Li W, Zeng S, Yu LS, Zhou Q. Pharmacokinetic drug interaction profile of omeprazole with adverse consequences and clinical risk management. Ther Clin Risk Manag. 2013;9:259-271.

17. Alexandra JF, Pautas E, Gouin-Thibault I, Siguret V, Loriot MA. Overanticoagulation with coumarin and cutaneous azole therapy. Ann Intern Med. 2008;148:633-635.

18. Horn JR, Hansten PD, Chan LN. Proposal for a new tool to evaluate drug interaction cases. Ann Pharmacother. 2007;41:674-680.
Therapeutics and Clinical Risk Management

\section{Publish your work in this journal}

Therapeutics and Clinical Risk Management is an international, peerreviewed journal of clinical therapeutics and risk management, focusing on concise rapid reporting of clinical studies in all therapeutic areas, outcomes, safety, and programs for the effective, safe, and sustained use of medicines. This journal is indexed on PubMed Central, CAS,

\section{Dovepress}

EMBase, Scopus and the Elsevier Bibliographic databases. The manuscript management system is completely online and includes a very quick and fair peer-review system, which is all easy to use. Visit http://www.dovepress.com/testimonials.php to read real quotes from published authors.

Submit your manuscript here: http://www.dovepress.com/therapeutics-and-clinical-risk-management-journal 